\title{
DETEKSI DINI DAN PENINGKATAN PENGETAHUAN LANSIA SEBAGAI UPAYA PREVENTIF TERJADINYA DIABETES MELLITUS DI DESA GANDUL CINERE
}

\author{
Andri Pramono ${ }^{1}$, Retno Yulianti ${ }^{1}$, dan Nanang Nasrulloh ${ }^{2}$ \\ ${ }^{1}$ Fakultas Kedokteran, Universitas Pembangunan Nasional Veteran Jakarta \\ Email: andri.pramesti@upnvj.co.id \\ ${ }^{2}$ Fakultas Kesehatan Masyarakat, Universitas Pembangunan Nasional Veteran Jakarta
}

\begin{abstract}
Diabetes Mellitus (DM) patients in Indonesia are ranked fourth in Asia and seventh in the world. In Depok, $15 \%$ of Depok residents suffer from DM. Low knowledge of the dangers and management of DM disease nutrition, as well as lack of early detection of DM disease, contributes to the severity and complications of the disease. This activity aims to reduce the prevalence and severity of DM in Gandul in a preventive way. The target audience in this activity are elderly women members of the Anggrek Bulan Gandul Posbindu and Posbindu Delima Senja, Gandul, Cinere. The implementation of this activity uses counseling and question and answer methods. Then monthly blood sugar detection is carried out monthly, and measurements of abdominal circumference and body weight to see symptoms of obesity. The enthusiasm of the participants was quite good seen from the presence of the participants who came. Early detection is done regularly per month and found 2 (2 of 34 mothers) elderly mothers of Posbindu Anggrek Bulan and 4 elderly mothers in Posbindu Delima Senja (4 out of 30 mothers), who have type 2 diabetes. Knowledge about DM was measured by questionnaire. The results of the questionnaire showed 3 people (10\%) with good results, 4 people $(13.3 \%)$ with sufficient results, and 23 people (76.67\%) with poor results after counseling. This activity should be a routine monthly activity and a measurement of understanding is carried out with a questionnaire after giving the material, as well as making a DM booklet for elderly DM patients, so that they can re-read the material provided
\end{abstract} Keywords: diabetes mellitus; elderly, gandul village; posbindu

\begin{abstract}
ABSTRAK
Pasien Diabetes Mellitus (DM) di Indonesia menduduki peringkat keempat terbesar di Asia dan peringkat ketujuh di dunia. Di kota depok, sebanyak 15\% penduduk kota Depok menderita DM. Pengetahuan yang rendah tentang bahaya dan tatalaksana nutrisi penyakit DM, serta kurangnya deteksi dini penyakit DM, memberikan kontribusi keparahan dan komplikasi penyakit. Kegiatan ini bertujuan mengurangi tingkat prevalensi dan keparahan DM di Gandul dengan cara preventif. Khalayak sasaran dalam kegiatan ini adalah ibu-ibu lansia anggota posbindu Anggrek Bulan Gandul dan posbindu Delima Senja, Gandul, Cinere. Pelaksanaan kegiatan ini menggunakan metode penyuluhan dan tanya jawab. Kemudian diadakan deteksi gula darah secara berkala perbulan, dan pengukuran lingkar perut dan berat badan untuk melihat gejala obesitas. Antusiasme dari para peserta cukup baik dilihat dari kehadiran peserta yang datang. Deteksi dini dilakukan secara berkala per bulan dan didapatkan 2 (2 dari 34 ibu-ibu) ibu-ibu lansia Posbindu Anggrek Bulan dan 4 ibu-ibu lansa di Posbindu Delima Senja (4 dari 30 ibu-ibu), telah mengidap DM tipe 2. Pengetahuan tentang DM diukur dengan kuesioner. Hasil kuesioner memperlihatkan 3 orang (10\%) dengan hasil yang baik, 4 orang (13,3\%) dengan hasil cukup, dan 23 orang (76,67\%) dengan hasil buruk setelah penyuluhan. Kegiatan ini sebaiknya menjadi kegiatan rutin bulanan dan diadakan pengukuran pemahaman dengan kuesioner setelah pemberian materi, serta pembuatan booklet DM untuk para pasien DM lansia, agar dapat membaca kembali materi yang diberikan.
\end{abstract}

Kata kunci: diabetes mellitus; lansia, kelurahan gandul; posbindu.

\section{PENDAHULUAN}

Jumlah penderita DM di Indonesia menempati urutan keempat terbesar di Asia dan urutan ketujuh di seluruh dunia. Kota Depok di Indonesia, menduduki peringkat kedua terbanyak jumalh penderita DM. Sebanyak 15\% penduduk kota Depok menderita DM (PERKENI 2015). Kota Depok menduduki peringkat kedua terbanyak penderita diabetes mellitus se-Indonesia setelah Maluku Utara. Menurut Dinas Kesehatan Depok tahun 2017, dari seluruh rumah sakit yang ada di 
kota Depok, Diabetes Mellitus termasuk dalam pola 10 besar penyakit terbanyak pada pasien rawat jalan $(11,76 \%)$ dan rawap inap $(14,5 \%)$ serta penyebab kematian $(6,84 \%)$ (Dinkes, 2017).

Pengetahuan tentang bahaya dan deteksi dini DM masih sangat rendah. Banyak para lansia tidak menyadari bahwa sudah memasuki tahap pra DM, dan harus melakukan tindakan preventif untuk mencegah keparahan penyakit menjadi DM atau bahkan komplikasi. Hal tersebut dikarenakan kurangnya informasi uang dimiliki oleh masyarakat tentang Diabetes Mellitus. Kejadian Diabetes Mellitus berhubungan signifikan dengan obesitas. Gejala obesitas dapat dilihat dari lingkar perut secara tidak langsung. Hasil penelitian memperlihatkan bahwa ada hubungan antara tingkat pendidikan dengan kejadian obesitas sentral, yang berhubunngan secara tidak langsung dengan terjadinya Diabetes Mellitus (Karimah, M. 2018 dan Puspitasari, 2018). Selain itu, tingginya pengukuran gula darah sewaktu $\geq 200 \mathrm{mg} /$ dLdisertai dengan gejala poliuria, polidipsia, polifagia, dan penurunan berat badan yang tidak dapat dijelaskan sebabnya, dapat menjadi indikasi adanya penurunan fungsi insulin dan mulai terjadinya pra-DM (PERKENI, 2015 dan Soegondo S, dkk, 2019).

Posbindu Anggrek Bulan dan Posbindu Delima Senja berada di RW 05 Kelurahan Gandul, Kecamatan Cinere, Kota Depok. Kelurahan Gandul memiliki luas $289 \mathrm{Ha}$, terdiri dari 224,1 Ha sebagai pemukiman, 35,1 Ha untuk halaman dan 4,1 Ha sebagai lapangan. Sebanyak 77,5\% dari total luas lahan di desa Gandul adalah pemukiman warga (BPS kota Depok, 2017). Kecamatan Cinere merupakan wilayah terkecil di kota Depok dengan luas $10,68 \mathrm{~km}^{2}$ dan kepadatan penduduk mencapai 13.038 orang $/ \mathrm{km}^{2}$ (BPS kota Depok, 2017). Puskesmas Cinere sebagai fasilitas kesehatan pemerintah, memiliki fasilitas meliputi layanan dokter umum dan ruang tindakan, manajemen terpadu balita sakit (MTBS), poli gigi dan mulut, kesehatan ibu dan anak (KIA), imunisasi, keluarga berencana $(\mathrm{KB})$, poli $\mathrm{TB}$, poli kesehatan ibu, poli lansia, serta fasilitas penunjang seperti laboratorium, praktek bidan, apotik, posyandu dan posbindu. Kelurahan Gandul memiliki 8 posbindu. Posbindu Anggrek Bulan merupakan salah satu posbindu di kelurahan Gandul yang beranggotakan 34 ibu-ibu lansia dengan sebagian besar hanya berpendidikan SD (91,17\%), sedangkan Posbindu Delima Senja beranggotakan 30 ibu-ibu lansia yang juga sebagian besar hanya berpendidikan SD $(93,3 \%)$. Rendahnya tingkat pendidikan, penghasilan dan kurangnya fasilitas kesehatan untuk pencegahan penyakit degeneratif, merupakan faktor-faktor resiko terjadinya penyakit degeneratif. Hal ini yang menjadi latarbelakang permasalahan Posbindu di kelurahan Gandul, sehingga perlu diadakan deteksi dini Diabetes Mellitus secara berkala dan disertai dengan peningkatan pengetahuan tentang Diabetes Mellitus. Tujuan dari pelaksanaa kegiatan ini adalah meningkatkan kewaspadaan masyarakat, khususnya di Kelurahan GandulDepok, tentang bahaya Diabetes Mellitus, faktor-faktor pemicunya dan upaya preventif yang bisa dilakukan untuk menghindarinya.

\section{METODE KEGIATAN}

Metode yang digunakan untuk pemecahan permasalahan ini adalah :

a. Pemberian materi kepada ibu-ibu lansia Posbindu Anggrek Bulan mengenai diabetes mellitus.

b. Melakukan tes dengan kuesioner setelah diberikan penyuluhan untuk mengukur pengetahuan ibu-ibu lansia di Posbindu Anggrek Bulan mengenai diabetes mellitus.

c.Focus Group Discussion (FGD) dengan ibu-ibu lansia Posbindu Anggrek Bulan untuk evaluasi keberhasilan kegiatan.

d. Pemeriksaan gula darah, berat badan, dan lingkar perut secara berkala perbulan untuk mendeteksi gejala pra-DM. 
Materi Penyuluhan :

1. Diabetes mellitus

2. Faktor-faktor penyebab diabetes mellitus

Media yang digunakan :

1. Posttest setelah penyuluhan

2. Presentasi materi dengan menggunakan laptop dan infokus. Materi dipresentasikan dalam bentuk powerpoint.

\section{HASIL DAN PEMBAHASAN}

Kehadiran peserta pada saat penyuluhan ada 30 orang. Antusias peserta cukup baik terhadap kegiatan penyuluhan ini, hal ini dibuktikan dari banyak tanya jawab yang dilakukan dengan peserta. Pelaksanaan kegiatan dilakukan dengan presentasi menggunakan in focus, disertai dengan gambar-gambar yang lebih mudah dipahami oleh ibu-ibu lansia. Peserta menyebutkan bahwa penyuluhan ini sangat bermanfaat untuk mereka dan berkeinginan untuk menerapkan pola hidup sehat untuk lansia di kehidupan sehari-hari agar dapat mencegah terjadinya penyakit degeneratif seperti Diabetes Mellitus.

Kegiatan penyuluhan diberikan dengan memberikan penjelasan tentang penyakit definisi penyakit Diabetes Mellitus. Di dalam penyuluhan diberikan penjelasan tentang penyebab penyakit Diabetes Mellitus, gejala terjadinya Diabetes Mellitus, tindakan preventif agar tidak terjadi Diabetes Mellitus, faktor-faktor resiko pemicu penyakit Diabetes Mellitus, prevalensi kejadian di masyarakat, pemeriksaan Diabetes secara berkala hingga diagnosis dan pengobatan yang harus dijalani seumur hidup jika sudah mengidap penyakit Diabetes Mellitus tipe 2. Penyuluhan dilakukan dengan pemberian presentasi dengan power point dan tanya jawab interaktif, lalu dilanjutkan dengan sesi tanya jawab dan Forum Group Discussion untuk mendapatkan feedback dari para peserta. Sebagian besar peserta sangat antusias dalam mendengarkan ilmu yang diberikan dan menginginkan kegiatan ini dilakukan secara berkala dan terus menerus.

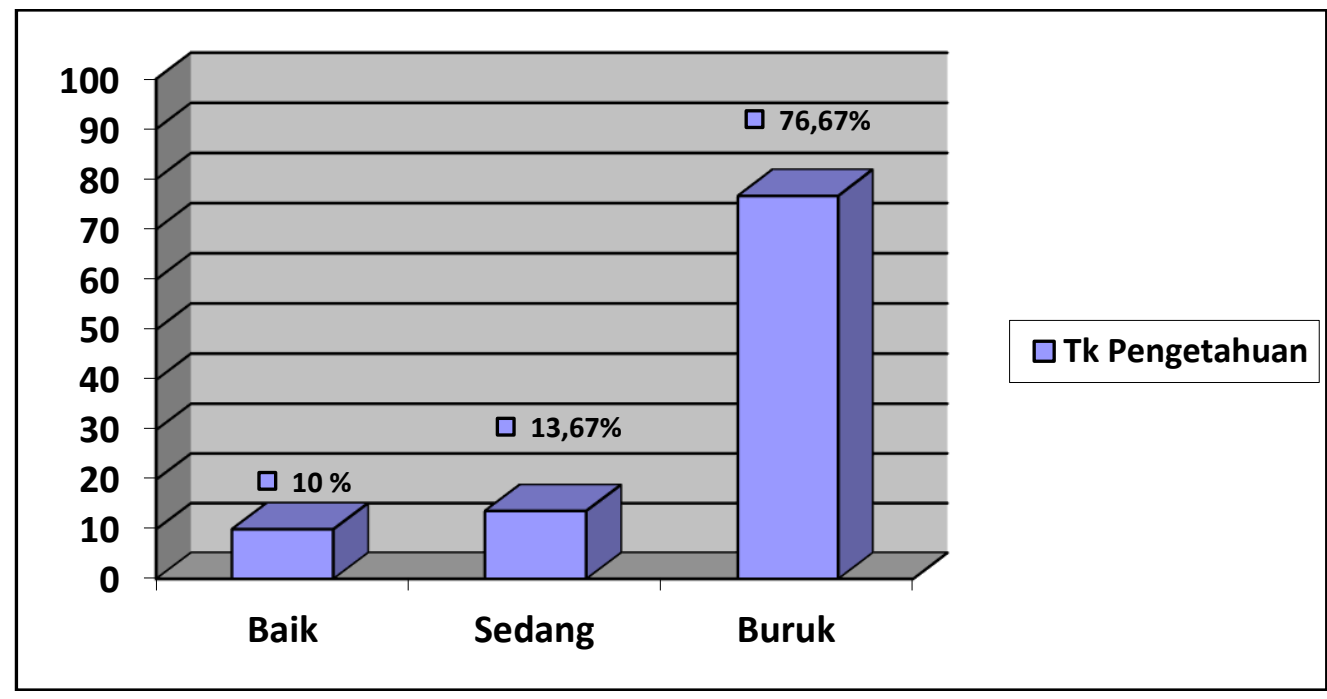

Gambar 1. Tingkat Pengetahuan lansia setelah penyuluhan

Setelah dilakukan penyuluhan, tingkat pemahaman ibu-ibu tentang penyakit Diabetes Mellitus diukur dengan menggunakan kuesioner. Kuesioner terdiri dari 20 pertanyaan untuk mengukur pengetahuan umum tentang Diabetes Mellitus dan pola hidup sehat yang seharusnya dilakukan oleh para ibu lansia untuk preventif terjadinya gejala penyakit tersebut. Pretest dinilai dengan langkah sebagai berikut : pertanyaan yang dijawab dengan benar mendapatkan skor 1, jika jawaban 
salah akan mendapat skor 0. Jumlah skor dijumlahkan, selanjutnya diprosentasekan dengan dikalikan dengan $100 \%$. Hasil prosentase dikategorikan baik bila nilainya $>66 \%$, dikategorikan sedang bila nilainya diantara $33-66 \%$, dan dikategorikan buruk bila $<33 \%$.

Analisa berupa Univariat (Gambar 1), dan didapatkan bahwa 10\% peserta memiliki pengetahuan baik, 13,67\% memiliki pengetahuan sedang dan 76,67\% memiliki pengetahuan buruk setelah mendapatkan penyuluhan. Hal ini dapat dikarenakan tingkat pendidikan ibu-ibu lansia yang rendah, sehingga membutuhkan pengulangan penyuluhan secara berkala serta pendampingan yang lebih intensif secara terus menerus. Para peserta banyak yang memberikan komentar bahwa ilmu tentang Diabetes Mellitus ini sangat baik untuk diberika kepada para lansia, tetapi diharapkan dapat diberikan dengan bahasa yang lebih sederhana dan mudah dipahami oleh orang awam. Kemudian banyak ibu-ibu yang tidak dapat membaca dan menulis dengan baik walaupun sudah pernah menempuh pendidikan SD, hal ini dikarenakan tidak terbiasanya ibu-ibu untuk sering membaca, terutama membaca tentang ilmu pengetahuan kesehatan. Diharapkan kegiatan berkala seperti ini dapat menambah pengetahuan para lansia tentang kesehatan, khususnya tentang penyakit degeneratif seperti Diabetes Mellitus. Gambar 2, menunjukkan tim abdimas dan sebagian peserta sebelum kegiatan.

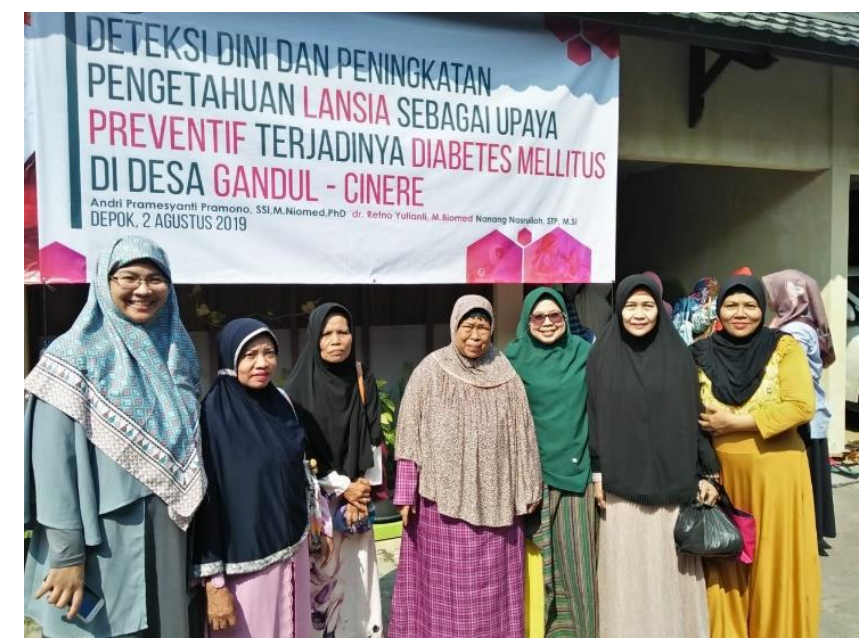

Gambar 2. Tim abdimas dan sebagian peserta sebelum kegiatan.

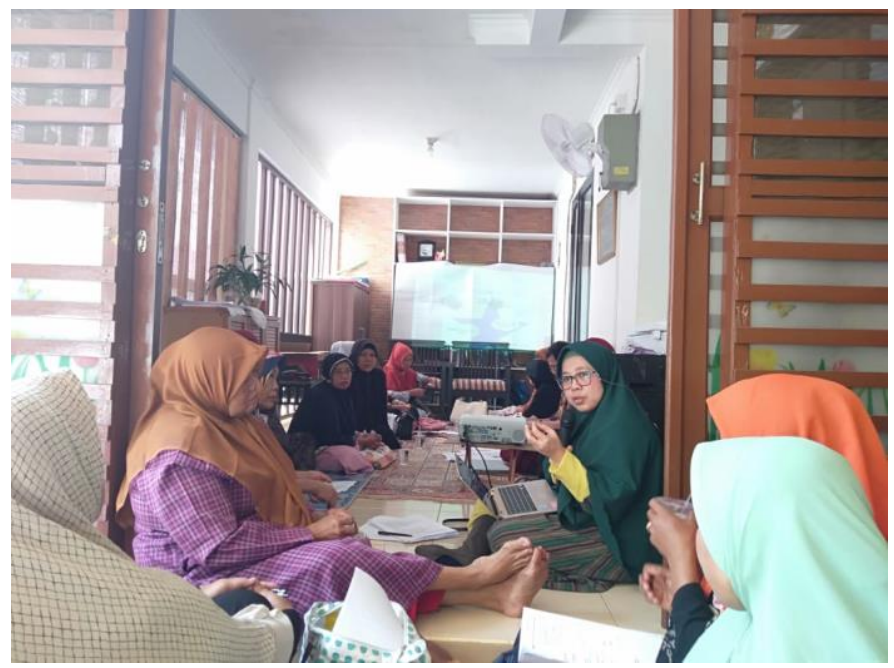

Gambar 3. Kegiatan Penyuluhan 
Tabel 1. Lingkar Perut

\begin{tabular}{ccc}
\hline Keterangan & Jumlah $(\mathrm{n})$ & Kategori \\
\hline$>80 \mathrm{~cm}$ & 19 & Gemuk \\
$<80 \mathrm{~cm}$ & 11 & Normal \\
\hline Jumlah & 30 & \\
\hline
\end{tabular}

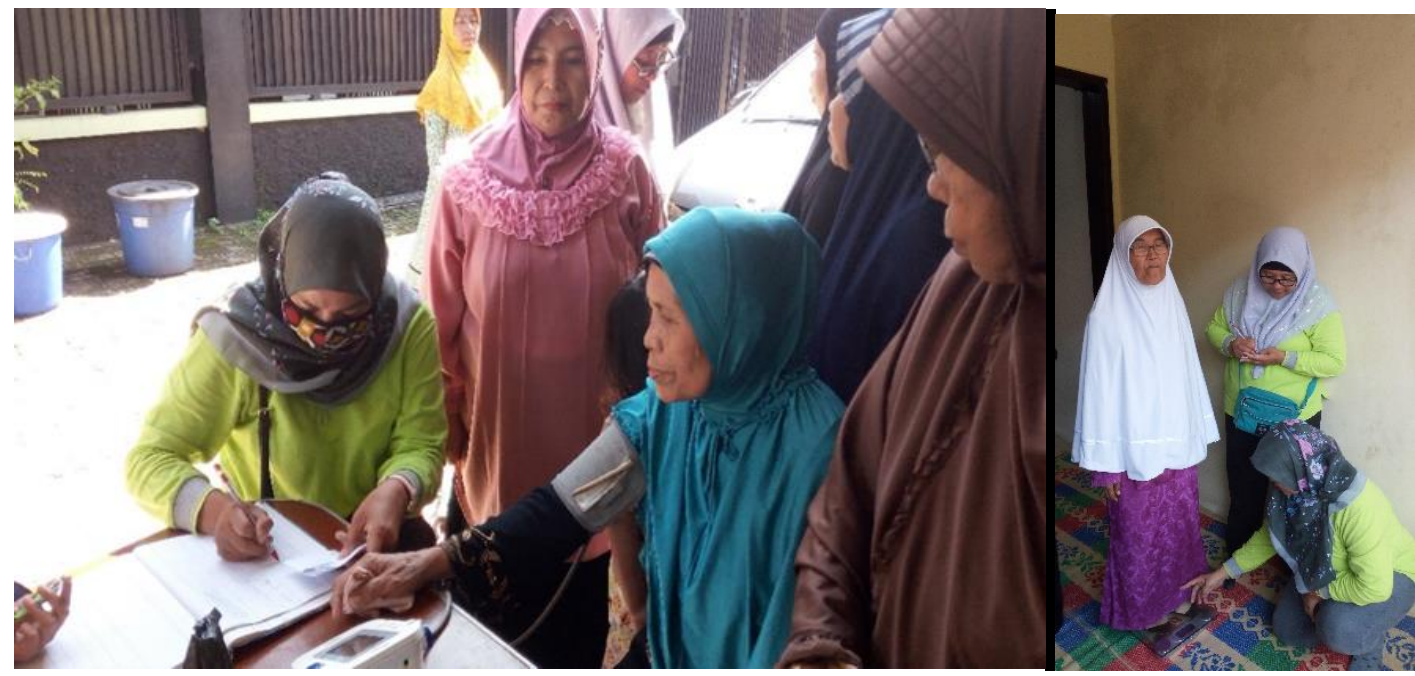

Gambar 4. Kegiatan Deteksi Dini Penyakit Degeneratif

Kegiatan penyuluhan berjalan lancar dan baik (Gambar 3), sesuai dengan waktu yang diharapkan. Setelah kegiatan penyuluhan, lalu dilakukan tanya jawab dengan para peserta. Setelah tanya jawab, lalu dilanjutkan dengan pengukuran berat badan, lingkar perut dan pengukuran gula darah (Gamabr 4). Pada posbindu Anggrek Bulan dijumpai 2 (2 dari 34 ibu-ibu) ibu-ibu lansia telah menderita Diabetes Mellitus tipe 2, sedangkan pada Posbindu Delima Senja ada 4 (4 dari 30 ibuibu) ibu-ibu lansia yang sudah terkena Diabetes Mellitus tipe 2.

Pengukuran lingkar perut dari 30 ibu-ibu dari Posbindu Anggrek Bulan dan Posbindu Delima Senja memperlihatkan sebanyak $19(63,3 \%)$ ibu-ibu lansia memiliki lingkar perut lebih dari $80 \mathrm{~cm}$ (Tabel 1). Hal ini memperlihatkan bahwa lebih dari 50\% ibu-ibu memiliki gejala obesitas dan perlu waspada agar tidak terjadi Diabetes Mellitus.

\section{KESIMPULAN DAN SARAN}

Kegiatan deteksi dini dan peningkatan pengetahuan lansia tentang Diabetes Mellitus telah dilaksanakan dan diterima dengan baik oleh kader kesehatan dan warga di Posbindu Anggrek Bulan dan Delima Senja, di Keluarahan Gandul, Cinere, Depok. Para peserta mendapatkan pengetahuan, walaupun masih belum maksimal. Oleh karena itu maka kegiatan penyuluhan ini akan dilakukan secara berkala untuk meningkatkan pengetahuan para lansia dan meningkatkan upaya preventif untuk mencegah terjadinya penyakit Diabetes Mellitus.

Direncanakan kegiatan ini akan menjadi kegiatan rutin bulanan yang akan diadakan di Posbindu Anggrek Bulan dan Delima Senja, dan akan diadakan pengukuran pemahaman dengan kuesioner setelah pemberian materi, serta pembuatan booklet DM untuk para pasien DM lansia, agar dapat membaca kembali materi yang diberikan. 


\section{Ucapan Terima Kasih}

Kami mengucapkan terima kasih kepada LPPM Universitas Pembangunan Nasional Veteran Jakarta atas dukungannya dalam pelaksanaan kegiatan PKM ini. PKM ii dibiayai oleh dana DIPA dari UPNVJ berdasarkan surat SK. Ucapan terima kasih kami berikan juga kepada pihak Kelurahan Gandul Cinere dan Kampung KB Kelurahan Gandul RW 05, Kecamatan Cinere, yang telah bekerjasama dalam kegiatan ini.

\section{REFERENSI}

Perkumpulan Endokrinologi Indonesia. Konsensus Pengendalian dan Pencegahan Diabetes Mellitus Tipe 2 di Indonesia. PERKENI 2015.

http://dinkes. Depok.go.id/wp-content/uploads/PROFIL-KESEHATAN-KOTA-DEPOK2017.pdf. dirujuk pada tanggal 14 September 2019.

Karimah, M. 2018. RASIO LINGKAR PINGGANG-PANGGUL MEMILIKI HUBUNGAN PALING KUAT DENGAN KADAR GLUKOSA DARAH. Jurnal Berkala Epidemiologi. Vol.3(6) :219-226.

Puspitasari, N. 2018. Faktor Kejadian Obesitas Sentral Pada Usia Dewasa. Higeia Journal of Public Health, Research and Development. Vol 2 (2) : 249-259.

Perkumpulan Endokrinologi Indonesia. Konsensus Pengendalian dan Pencegahan Diabetes Mellitus Tipe 2 di Indonesia.PERKENI 2015.

Soegondo S, Soewondo P, Subekti I. Penatalaksanaan diabetes melitus terpadu. Edisi ke-2. Jakarta: Balai Penerbit FK UI; 2009. p. 13, 15-6, 33- 44, 123-6, 152, 155-6.

BPS kota Depok. 2014. Statistik Daerah Kecamatan Cinere 2014. Badan Pusat Statistik Kota Depok: $\mathrm{x}+31$ hal.

BPS kota Depok. 2014. Kecamatan Cinere dalam angka 2014 :Cinere district in figures. BPS Kota Depok: ix +65 hal. 